\title{
Cohort analysis of adolescent first birth timing and births progression in West-Africa
}

\author{
Adebowale Ayo Stephen ${ }^{1,2}$, Bamgboye Eniola ${ }^{1}$, Adjiwanou Visseho ${ }^{3}$ \\ ${ }^{1}$ Department of Epidemiology and Medical Statistics, Faculty of Public Health, \\ College of Medicine, University of Ibadan, Ibadan, Nigeria \\ ${ }^{2}$ Visiting Academic Centre for Actuarial Research (CARe), Faculty of Commerce, \\ University of Cape Town, Cape Town, South Africa \\ ${ }^{3}$ Centre for Actuarial Research (CARe), Faculty of Commerce, \\ University of Cape Town, Cape Town, South Africa \\ Email: Adehamilt2008@yahoo.com
}

\begin{abstract}
Context/Background: Adolescent Childbearing is an important factor sustaining high; fertility, childhood mortality and maternal mortality in West-Africa. We examined cohort analysis of adolescent first birth (AFB) timing and births progression in West-Africa.

Data Source and Methods: Most recent round of DHS data of four countries in West-Africa were used. Women aged 20-49 years were studied. Birth timing probability, birth progression rate and hazard ratio were estimated $(\alpha=5.0 \%)$.

Results: Across countries, AFB increases as the women's year of birth cohort increases and the rate was highest among Nigerian women $(r=0.773, p<0.00 \mathrm{I})$ but lowest in Liberia $(r=0.497, p<0.00 \mathrm{I})$. The probability of surviving adolescent years' interval without bearing a child was highest in Ghana for all age-cohorts, while Nigeria and Liberia exhibited similar pattern. Birth progression rate was higher among women who had AFB than women who started theirs at the later years. Hazard ratio of AFB was higher among women in age cohort 20-24 than those aged 45-49 years.

Conclusion: Adolescent first birth is a problem in West-Africa but variation exist in the region. Adolescent pregnancy prevention policy is solicited in West-Africa.
\end{abstract}

Keywords: First birth timing, Adolescent women, Birth progression, Adolescent pregnancy, WestAfrica

\section{Introduction}

West Africa is one of the regions with high fertility rate world-wide (Population Reference Bureau, 2016). Nearly all the countries in West Africa have their Total Fertility Rate (TFR) higher than 5.0. An indication that fertility transition which has begun in some parts of sub-Saharan Africa is yet to commence in West-Africa (Population Reference Bureau, 2016). In Southern Africa for instance, countries like South Africa (TFR=2.4) and Botswana (TFR=2.8) are already in transition compared to West African countries like Niger (TFR=7.6), Burkina Faso (5.7) and Mali (6.0) which have been categorized among the top ten high fertility countries world-wide (Population Reference Bureau, 2016). This has implication on demographic dividends and attainment of Sustainable Development Goals (SDGs) in the countries in the region (The Statistical Annex, 2017). Consistent reporting of high fertility among countries in West Africa is likely to be one of the reasons for low level of economic growth and development in the region (The Statistical Annex, 2017).

Many factors have been substantiated as being responsible for fertility differential among which adolescent childbearing has been consistently reported even in the developed countries (Oyefara, 20 I2; Ashraf, 2005; Hans-Peter, 200 I; Marini, I98I). Cultural factors like early marriage, gender disparity in education, social taboos around sexual matters are instrumental to high adolescent fertility in West Africa (Oyefara, 2012; Isiugo-Abanihe, 1985). Other factors associated with adolescent fertility include low modern contraceptive prevalence rate, poverty and lack of political will on the part of leaders (International Planned Parenthood Federation, 20I2).

Africa has the world's highest rates of adolescent fertility (UNFPA, 2013). The issue of persistent reporting of high adolescent childbearing rate in Africa countries has generated an unparalleled research controversyand much of that controversy revolves around the claim that high adolescent 
childbearing rate is associated with increased fertility. However, in countries like South Africa and Botswana where high adolescent childbearing rate has been reported, their level of fertility still remains lower than that of some countries in sub-Saharan Africa with lower adolescent childbearing rate (Population Reference Bureau, 2016). One can argue that once a woman has the first birth particularly if the child is born out of wedlock as in most cases of adolescent childbearing in Southern Africa, there is tendency for her to delay in proceeding to further childbearing. This delay might result from one or more of the following; timing for an adolescent mother to search for a new partner who will marry her as a single mother, availability of social security supports for single mothers from government, her previous childbearing experience believing it is better to abstain from sexual relations with men till she gets a good and reliable husband. Although, the delay can be overturned if she has little or no means of livelihood to sustain herself and the baby and therefore she might fall as prey into the hands of deceitful suitors.

In this study, attention was focused on adolescent childbearing because of its adverse socio-economic and health effects on the population (Eshetu and Dula, 2014; Pirk et al., 2014; Gibbs et al., 2012; Schuyler Center for Analysis and Ad, 2008). Poor health conditions characterized teen mothers in developing countries where they might likely experiencehigher inadequate dietary intake, poor physical growth, obstructed labor, lack of access to good health services and maternal mortality than older mothers (Zabin, 1998). Adolescent childbearing often leads to; loss of educational opportunities, poor access to ANC, parental rejection, sexual partner's rejection if unmarried, societal stigmatization, psychological distress and maternal poor health outcomes (Gibbs et al., 2012; Alan Guttmacher Institute, 1996). Babies born by adolescent mothers are likely to have low birth weight, malnourished, stunted, having inadequate care with high morbidity and mortality (Pirk et al., 20 I4; Haaga, 1989). At the family level, if such birth occurs outside wedlock, it can lead to shame on the part of family members from the community, aggravate poverty and overstressing of the little family resources (Blum et al., 20l4; MEASURE DHS, 20I5). Adolescent childbearing often leads to overpopulation, high fertility rate, high childhood mortality rate, low life expectancy and halt demographic transition as some countries in West Africa are currently experiencing (Population Reference Bureau, 2016).

Early sexual initiation are common practices among adolescent in West-Africa countries (Measure DHS). Conscious of this fact, nearly all the countries 4515 in the region have signed a number of international and regional human rights laws and they have introduced national legislation to protect the rights of girls (International Development Law Organization, 2010; United Nations, 2015). Yet, adolescent childbearing remains high in the region perhaps because some of the enacted child right laws are passive. Adolescent childbearing is an important contemporary issue in West Africa because the region has the slowest pace in fertility transition in sub-Saharan Africa (PRB, 2016). In this Africa subregion, childbearing starts early and continues throughout the reproductive ages. Investigation of trend in adolescent childbearing will help to figure out whether there is future potential for fertility transition in West Africa. In addition, a major programme and policy worry is on the factors influencing adolescent fertility. Studies have identified several factors like place of residence, household wealth, age at first sexual debut, etc in explaining adolescent fertility in some West-African countries (Adebowale et al., 2016; Sarah et al., 2015; Oyefara, 2012; Mturi, 2015; Sneeringer, 2009; Garenne, 2008) but there is gap in literature on cohort and trend analysis of adolescent childbearing in the region. This study therefore aims at determining the rate and trend of adolescent childbearing among four purposefuly selected countries in West-Africa. In addition, parity progression ratio of the women aged 45-49 years was examined for each of the selected countries.

\section{Literature review and theoretical framework}

In Africa, priority has been given to childbearing among other reasons for marriage. In sub-Saharan Africa in particular, every childless marital union stands higher chances of dissolution and women are mostly the childbearing agitators. The common statement "Woman who owns children owns the world" often puts women in West Africa under pressure to have at least a biological child. In some cultures, in the region, people still tagged infertility to previous immoral acts of sexual behavior like abortion, sexually transmitted infections and host of others. Consequently, an infertile woman is often stigmatized or ostracized in the society and seen as a subject of ridicule among other women (Magezi, 2017; Balen and Bos, 2009). Despite the significance of childbearing, the age at which first birth occurs is very important. While this may not really raise any issue among older women, it has serious implications among adolescents. Adolescent childbearing is an important indicator of women's current and future socioeconomic status (UN, 20l3). Based on this background, issues around adolescent fertility in West-Africa remain important. Countries in West

http://aps.journals.ac.za 
Africa predominantly have young population as reflected in the shape of their population pyramids (PRB, 20I6). The rising in numbers of adolescent in West-Africa is likely to shape any future changes in the fertility timing or quantum and population growth in sub-Saharan Africa. The adolescents are critical cohort in fertility transition in West-Africa and they constitute the leading edge in the anticipated quick changes in reproductive behavior.

World-wide adolescent fertility has declined in the last three decades (United Nations, 201 I; Sedgh et al., 20I5). This decline was prominent among some sub-Saharan African countries like Cameroon, Kenya, Senegal and Tanzania. Countries like Burkina Faso, Central African Republic and Ivory Coast which had experienced high adolescent childbearing since 1970s have also witnessed decline in adolescent fertility (United Nations, 20II; Sedgh et al., 2015). In the early part of the immediate past decade, there are countries in sub-Saharan Africa where adolescent childbearing declined rapidly. These include; Benin, Cameroon, Eritrea, Ethiopia, Gabon, Ghana, Kenya, Namibia, Nigeria, Rwanda, Senegal, Tanzania, and Uganda (United Nations, 20II). Despite the reduction in the level of adolescent childbearing in these countries, the pace of declination is considerably low and their prevalence high by world standards (Population Reference Bureau. 2013; United Nations, 20II). The important reasons for decline in adolescent fertility in sub-Saharan Africa included marriage postponement, increase in female school enrolment and increase in contraceptive adoption (PRB, 2016; World Population Prospect, 2016).

Globally, in 1990s, adolescent fertility rates range from a low of 4 births per year per 1,000 women aged 15 to 19 in Japan to a high of over 200 in Niger and Uganda (Mensch et al., 1998). Within the developing world, adolescent fertility was found to be highest in sub-Saharan Africa, but some of the countries in South Asia and Latin America equally experienced high adolescent fertility rates of above 100 (Mensch et al., 1998). A more recent study in sub-Saharan Africa showed that 29 of 51 countries had adolescent birth rates of at least 100 in 20052010 , and these are concentrated in Middle Africa and Western Africa with the reported rates of 144 and 124 births per 1,000 women, respectively. The adolescent birth rate of 210 births per I,000 women aged 15 to 19 found in Niger was the highest among the countries. The region as a whole has an adolescent birth rate of 117 births per I,000 women aged 15 to 19 (2005-20I0) (United Nations, 2013; Santelli et al., 2016).

In sub-Saharan Africa, while previous studies mainly investigated determinants of adolescent pregnancy, not many focused on adolescent childbearing (Odimegwu and Mkwananzi, 2016; Adebowale et al., 20I6). Although, pregnancy leads to childbearing, therefore studies on adolescent childbearing may imitate and pass the same policy implications as that of adolescent pregnancy. In a study of contextual factors associated with teenage pregnancy in sub-Saharan Africa using DHS data, the researchers found that teenage pregnancy decreased in East Africa, plateaued in West Africa and increased slightly in Southern Africa between 1992 and 2011 (Odimegwu and Mkwananzi, 20l6). Clark et al. (2017) study showed an increase in the levels of premarital fertility by up to $13 \%$ in some African countries while others have experienced $7 \%$ decline (Clark et al., 2017). However, the authors found that other factors such as delayed sexual debut and the use of contraception counteract this effect.

The age at which first birth occurs is central to the overall level of fertility particularly if such births take place during adolescent period (Population Reference Bureau, 2016). It is an important determinant of completed family size under a natural fertility regime. In many countries where high early childbearing rate is observed, high total fertility rate is recorded (Population Reference Bureau, 2016) and childbearing during adolescent years often have adverse socio-economic implications (Adebowale et al., 2016; Letícia and Molly, 2013). This current study complements the existing literature on adolescent fertility in West-Africa. Thus, the policy makers in this Africa sub-region will find the outcome of this study valuable while designing programmes that are geared towards fertility reduction.

\section{Data and methods \\ Study countries}

The study was conducted in four purposefully selected West-Africa countries. These are; Nigeria, Ghana, Liberia and Gambia. The countries were selected based on data availability, fertility level and preference was given to countries where surveys were conducted at the same period. Therefore, two countries with TFR of at least 5.5 (Nigeria (TFR $=5.5$ ) and Gambia $($ TFR =5.7)) and two others with TFR below 5.0 (Ghana (TFR=4.2) and Liberia (TFR=4.7)) were selected. Standard Demographic Health and Survey (DHS) data were used for this study. Thus, 2013 DHS data was used for Nigeria, Liberia and Gambia while 2014 DHS was used for Ghana. The TFR used for selection of the countries into this study was based on the above stated survey year. Nigeria is the most populous country in West Africa with the population figure of above 186.4 million, the Ghanaian's population is 28.2 million, Gambia (2.I 
million) and Liberia (4.6 million) (Population Reference Bureau. 2016).

\section{Study design and sample extraction}

A cross-sectional population based design approach was used for this study. The survey data-sets used across the countries were generated by the same institution (ICF Macro) in conjunction with the population affairs parastatals in each of the selected country. Cluster design approach was used for data collection in all the countries (MEASURE DHS, 20I5). The sample used for each of the selected countries was lower than the actual sample selected during the field work (women without information on age at first birth were excluded). Also excluded were women with missing information on age and year of birth. Further excluded were women aged $<20$ years. Their exclusion became necessary because, these women are still adolescent and one cannot say accurately what their childbearing status would be at the end of adolescent period. Thus the sample size used for each country was 31043, 7640, 7770 and 7324 For Nigeria, Ghana, Gambia and Liberia respectively. A sub-sample of $3555,870,57$ and 807 was used to assess the parity progression ratio among women aged 45-49 years in Nigeria, Ghana, Gambia and Liberia respectively.

\section{Variable description}

The dependent variable was Adolescent First Birth (AFB) defined in this study as having the first child at ages below 20 years. In this case, date of birth of the first child, exact age of the mother in days and months, date and month when the survey was conducted were reconciled to arrive at the age of woman at first birth. Cross-checking of this newly generated variable with the variable V2 I 2 (age at first birth) in the original data-set was done for accuracy and error minimization. The final variable arrived at was categorized into two;

Age at first birth $=\left\{\begin{array}{l}x=1, \text { if age at first birth is less than } 20 \text { years } \\ x=0, \text { if age at first birth is } 20-49 \text { years }\end{array}\right.$

The status $x=I$ representing adolescent first birth is the main indicator of this study. The main independent variable is the age in years and this was examined as birth cohorts of women. For instance, women who were 20 years at the time of the 2013 survey were born in 1993. In this context, the date of birth was reconciled with the timing of the survey to get the actual year of birth. The year of first birth of each woman was also obtained in the same manner. During further analysis, explanatory variables like; place of residence, household wealth, religion and 4517 level of education were used. Other variables like region, ethnicity, age at first sexual intercourse and age at first marriage were not included in the analysis because, the nomenclature of ethnicity and region varies across the countries. Also, some women had their first birth before marriage and even some who had birth have not got married. As for the variable age at first sexual intercourse, it was not well captured in the survey data. Non-inclusion of these variables in the multivariate analysis was considered as major limitation to this study.

\section{Data analyses}

The data were weighted before use. The proportion of women who had their first birth at ages $<20$ years $\left(y_{t}\right)$ by the year of birth of cohort $(x)$ of women was estimated. The correlation and regression (equation I) parameters $\zeta_{0}$ and $\zeta_{1}$ were also estimated for this proportion and year of birth. This was used to obtain the adolescent first birth rate (equation 2 ) in each of the countries.

$$
y_{t}=\zeta_{0}+\zeta_{1} x+\varepsilon_{i}
$$

$$
\zeta_{1}=r_{t}=\frac{d\left(\frac{n_{c}}{N_{c}}\right)}{d t}
$$

Where; $\varepsilon_{i}$ is the error term, $n_{c}$ is the number of women in a cohort who had their ${ }^{\text {st }}$ birth before age 20 years and $N_{c}$ the total number of women in that cohort. Further, the survival probability (equation 3 ) of a woman having passed through adolescent period without first birth was estimated for the countries.

$$
S\left(t_{(j-1)}\right)=\prod_{i-1}^{j-1} P\left(T>t_{(i)} \backslash T \geq t_{(i)}\right)
$$

At the multivariate level of analysis, Cox-regression (equation 4) was fitted to examine the hazard ratio of AFB by age cohort as a measure of trend while controlling for other variables. The indicators used for this analyses were; time to event which is age at first birth in years, event status which was dichotomized as I if a woman had her first birth at ages $<20$ years and 0 if otherwise.

$$
\begin{array}{r}
\log \left\{h_{i}(t) / h_{0}(t)\right\} \\
=\beta_{1} x_{1 i}+\beta_{2} x_{2 i}+\cdots+\beta_{\eta} x_{\eta i}
\end{array}
$$

The coefficients $\beta_{1}, \beta_{2}, \ldots, \beta_{\eta}$ were estimated using maximum likelihood method. Estimates of the $\beta$ 's are values which are most likely on the basis of the observed data to predict adolescent first birth. In this case, there are $n$ women amongst whom are $K$ distinct AFB occurs at times $t_{(1)}, t_{(2)}, \ldots, t_{(k)}$, so that $t_{(i)}$ is the $\mathrm{i}$-th ordered first birth timing. There are $\mathrm{n}$ http://aps.journals.ac.za 
$\mathrm{K}$ right censored data and only one individual has first birth at ages $<20$ years so there are no ties. The set of individuals who are at risk at time $t_{(i)}$ is denoted by $R\left(t_{(i)}\right)$. The quantity $R\left(t_{(i)}\right)$ is the risk set. For the particular AFB at time $t_{(i)}$ conditionally on the risk set $R\left(t_{(i)}\right)$, the probability $(p)$ (equation 5 ) that the birth is the individually observed is;

$$
p=\frac{\exp \left\{\sum_{j=1}^{\eta} \beta_{j} X_{j i}\right\}}{\sum_{I \in R\left(t_{(i)}\right.} \exp \left\{\sum_{j=1}^{\eta} \beta_{j} X_{j i}\right\}}
$$

The sum on the denominator is over all individuals in the risk set at that time. Each of the $k$ adolescent birth contributes a factor and hence the conditional likelihood function for the data is the product of such expressions at all known AFB times and represented in equation (6)

$$
L(\beta)=\prod_{i=1}^{k}\left[\frac{\exp \left\{\sum_{j=1}^{\eta} \beta_{j} X_{j i}\right\}}{\sum_{I \in R\left(t_{(i)}\right.} \exp \left\{\sum_{j=1}^{\eta} \beta_{j} X_{j i}\right\}}\right]
$$

Thereafter, the conditional log-likelihood was obtained as shown in equation (7)

$$
\begin{aligned}
& L L(\beta) \\
& =\sum_{i=1}^{k} \sum_{j=1}^{\eta} \beta_{j} X_{j i} \\
& -\sum_{i=1}^{k} \log _{e}\left[\sum_{I \in R\left(t_{(i)}\right.} \exp \left\{\sum_{j=1}^{\eta} \beta_{j} X_{j i}\right\}\right]
\end{aligned}
$$

Maximum likelihood estimates of $\beta_{i}$ 's were obtained by solving equations (6) and (7) simultaneously.
Ethical approval and consent to participate

ICF International U.S.A approved the use of dataset. However, ethical approval to conduct the survey was granted by the appropriate ethical board of each of the countries included in this study. In addition, at the point of data collection, informed consent was sought and approved by all the study participants by signing the appropriate form during the data collection exercise. Each consenting participants was assured of confidentiality and anonymity of the information they provided.

\section{Results}

The data show that majority of the women had their first birth at adolescent age and this was mostly prevalent in Liberia $(76.2 \%)$, followed by Gambia (66.8\%), Nigeria (57.3\%) and Ghana (54.7\%).

In all the countries under investigation, adolescent first birth occurred mostly among women that were born between 1990 and 1993 and it increased steadily within the period. For instance, the range was $73.0 \%-98.2 \%$ among Nigerian women while it was $78.0 \%-96.3 \%$ in Gambia, $83.9 \%-97.5 \%$ in Liberia and $69.0 \%-79.4 \%$ in Ghana which seems to have the least distribution. In the wider spectrum of the birth cohort, cohort born in 197I (43.0\%) had the least proportion of women who had their first birth as adolescent in Nigeria, in Ghana it was 1975 (45.1\%) birth cohort while the 1968 (58.2\%) and 1972 (66.9\%) birth cohort were found in Gambia and Liberia respectively.

Across the countries, there was significant positive correlation between women's year of birth and proportion who had their first birth at ages below 20 years. Indicating that the proportion of women who had their first birth at ages $<20$ years increases with time or as the women's year of birth cohort increases. The rate at which the birth cohorts had their first birth was highest among Nigerian women

\begin{tabular}{|c|c|c|c|c|}
\hline \multirow{2}{*}{$\begin{array}{l}\text { Women's year } \\
\text { birth }\end{array}$} & Nigeria & Ghana & Gambia & Liberia \\
\hline & \multicolumn{4}{|c|}{ Proportion with first birth at ages $<20$} \\
\hline 1963 & $67.1(292)$ & & $78.1(299)$ & $73.2(698)$ \\
\hline 1964 & $53.3(401)$ & $63.0(46)$ & $68.5(4 \mid 7)$ & 74. I ( 1020$)$ \\
\hline 1965 & $52.6(263)$ & $51.6(399)$ & $59.9(445)$ & $79.8(768)$ \\
\hline 1966 & $53.1(205)$ & $53.1(557)$ & $68.9(385)$ & $73.6(665)$ \\
\hline 1967 & $56.3(450)$ & $49.7(382)$ & $60.2(610)$ & $75.4(731)$ \\
\hline 1968 & $52.0(360)$ & $49.0(376)$ & $58.2(410)$ & $73.2(931)$ \\
\hline 1969 & $46.0(198)$ & $57.6(684)$ & $63.9(436)$ & $72.6(563)$ \\
\hline 1970 & $50.2(339)$ & $51.2(464)$ & $69.7(718)$ & 77.7(735) \\
\hline
\end{tabular}
$(0.773, p<0.001)$ and least among Liberian women $(0.497, p<0.001)$.

Table I: Distribution of the women by their year of birth and proportion with first birth (as adolescent) at ages below 20 years according to selected countries in West Africa 


\begin{tabular}{lllll}
\hline $197 \mid$ & $43.0(188)$ & $56.1(389)$ & $64.9(465)$ & $75.9(902)$ \\
1972 & $50.2(527)$ & $57.9(769)$ & $64.5(872)$ & $66.9(900)$ \\
1973 & $52.3(523)$ & $46.6(298)$ & $66.2(647)$ & $77.7(1034)$ \\
1974 & $48.6(365)$ & $58.0(90 I)$ & $65.1(656)$ & $74.7(993)$ \\
1975 & $50.6(359)$ & $45.1(386)$ & $70.2(77 I)$ & $76.1(1076)$ \\
1976 & $47.6(297)$ & $50.9(525)$ & $67.1(623)$ & $75.0(825)$ \\
1977 & $52.1(708)$ & $53.0(502)$ & $63.0(1068)$ & $68.7(921)$ \\
1978 & $53.1(557)$ & $48.2(464)$ & $65.0(622)$ & $72.8(716)$ \\
1979 & $47.8(306)$ & $49.5(582)$ & $58.7(498)$ & $70.5(739)$ \\
1980 & $47.6(447)$ & $52.6(438)$ & $70.5(893)$ & $79.4(1076)$ \\
1981 & $50.9(290)$ & $57.1(402)$ & $64.0(701)$ & $75.9(507)$ \\
1982 & $57.6(879)$ & $53.2(450)$ & $66.5(894)$ & $77.4(1001)$ \\
1983 & $55.5(788)$ & $49.4(345)$ & $64.6(705)$ & $76.7(710)$ \\
1984 & $53.8(573)$ & $57.9(603)$ & $67.8(702)$ & $77.1(823)$ \\
1985 & $57.5(60 I)$ & $53.8(338)$ & $61.8(460)$ & $77.6(873)$ \\
1986 & $51.8(50 I)$ & $53.1(330)$ & $66.6(578)$ & $77.6(703)$ \\
1987 & $61.2(920)$ & $59.2(316)$ & $70.5(660)$ & $81.6(529)$ \\
1988 & $65.2(822)$ & $62.5(302)$ & $71.8(475)$ & $83.1(611)$ \\
1989 & $62.7(375)$ & $62.8(334)$ & $73.9(322)$ & $84.2(404)$ \\
1990 & $73.0(625)$ & $69.4(277)$ & $78.0(436)$ & $83.9(601)$ \\
$199 I$ & $70.4(45 I)$ & $73.2(219)$ & $78.6(213)$ & $89.9(311)$ \\
1992 & $86.0(863)$ & $74.8(193)$ & $89.7(393)$ & $91.9(410)$ \\
1993 & $98.2(586)$ & $79.4(135)$ & $96.3(103)$ & $97.5(155)$ \\
1994 & & $90.1(136)$ & & 76.2 \\
Total & 57.3 & 54.7 & 66.8 & $0.497 *$ \\
$r_{t}$ & $0.773 *$ & $0.729 *$ & $0.536 * *$ & $0.693 *$ \\
$\rho$ & $0.595 *$ & $0.645 *$ & $0.493 * *$ & \\
\hline
\end{tabular}

*Significant at $0.1 \%$; **ignificant at $1.0 \%$

Figure I shows that the proportion of women who had their first birth as adolescent was similar in pattern but the distribution varies across countries. The variation from the pattern exhibited by Ghana and Nigeria was prominent in Liberia and Gambia. Consistently, across the birth cohorts in all the countries, the Liberian women had highest proportion of their members bearing their first child as adolescent followed by Gambia while there were

Figure 2 depicts the pattern of the timing of first birth over years, the probability of surviving an interval without bearing first birth was highest in Ghana, while Nigeria and Liberia exhibited similar pattern and to some extent particularly in the later years, the pattern shown among Gambia women was similar to that of Nigeria and Liberia. As indicated in figure 2, between 1974 and 1977, the cohorts have begun childbearing in all the studied countries.

twists in the distribution for Ghana and Nigeria. 
Figure I: Distribution of women's birth cohort by proportion who had first birth as adolescent according to selected countries in West Africa

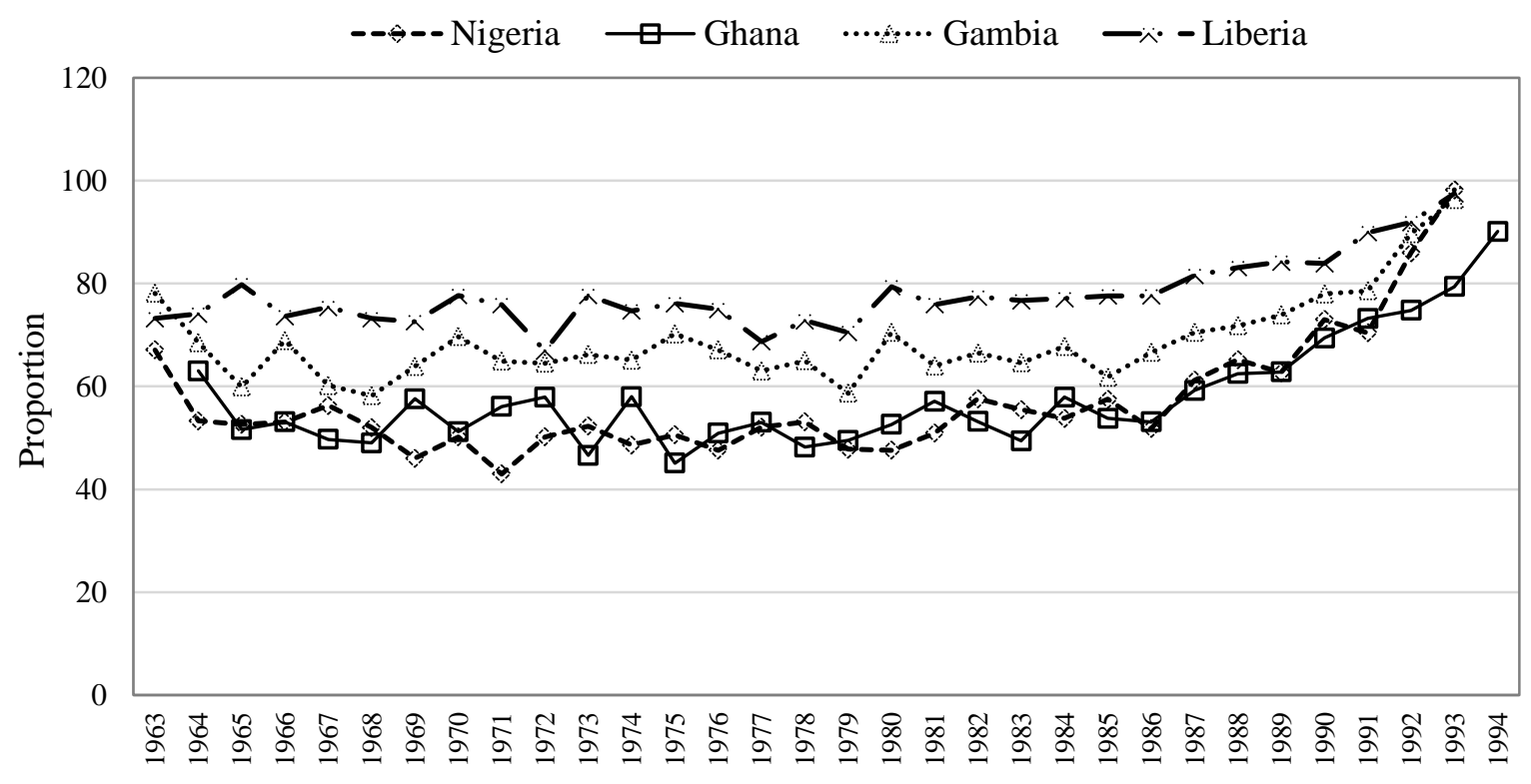

Women's birth cohort

Figure 2: Distribution of probability of surviving an interval without first birth by timing of first birth according to selected countries in West Africa

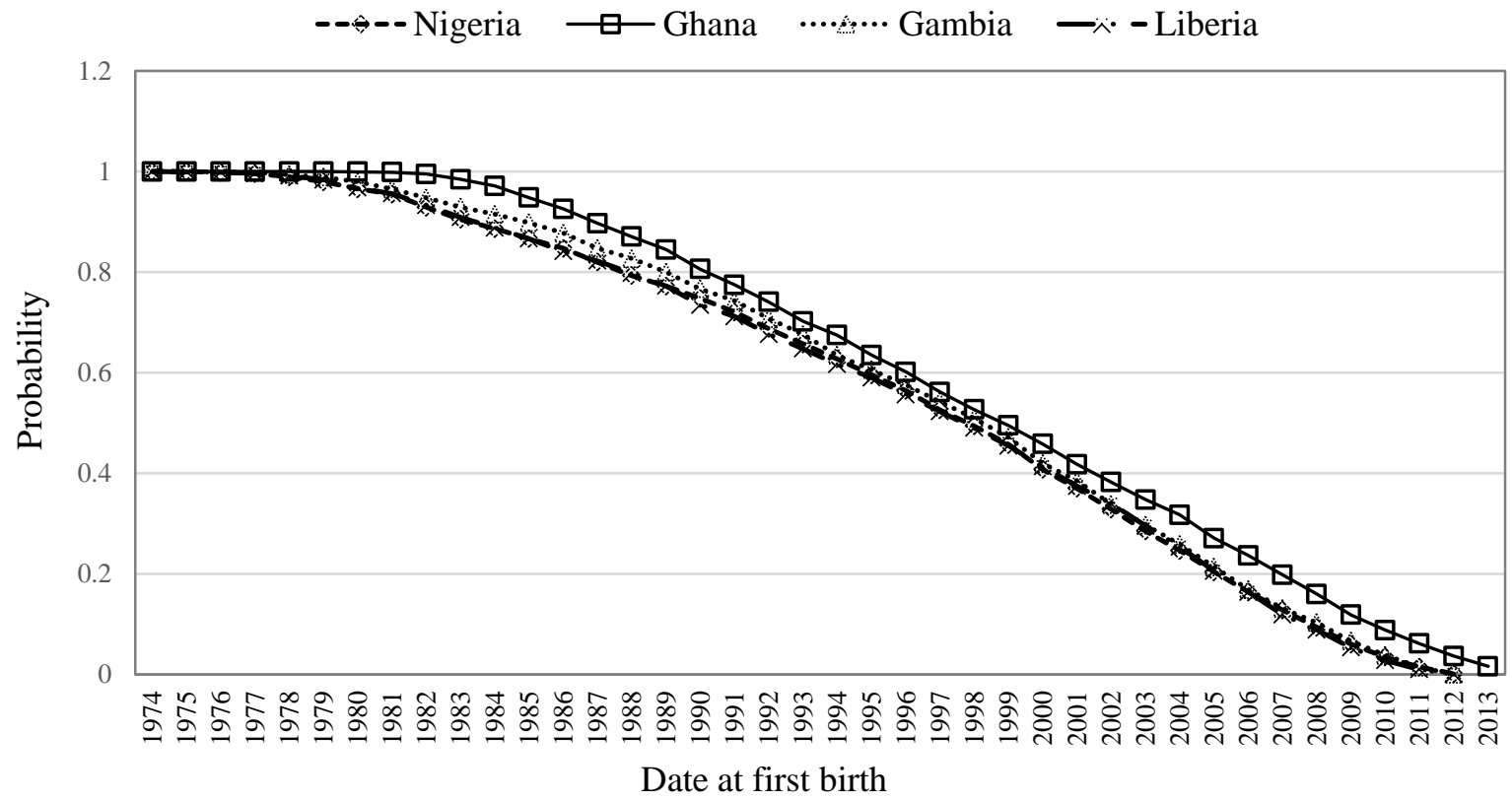

For women who had their first birth during adolescent years, the mean age at which the event occurs was similar in all birth cohorts of women and across countries (Table 2). In all the countries the mean age at first birth for women who began childbearing as adolescent approximates to 16 years in all the birth cohorts except in Ghana where the estimate was approximately 17 years. The mean age at first birth at any age varies across countries but with similar pattern exhibited by these countries. As expected, it was lowest among women age 20-24 year, closely followed by those in age group 25-29 years. In Nigeria, the mean age at first birth was highest among the cohort of women born in 40-44 years ago (19.16 44.4 years) whereas it was those in age group $35-39$ years (20.03 \pm 4.0 years) in Ghana, 45-49 years in Gambia (18.70 4.2 years) and 35-39 years among Liberian women (I7.98 \pm 3.4 years). When the analysis was conducted among women in age group 20-49 years, the mean age at first birth was 18.60 4.0 years in Nigeria, 19.58 \pm 3.8 years in Ghana, 18.39 \pm 3.7 years in Gambia and 17.75 \pm 3 
years in Liberia. The data further show that the mean age at first birth as an adolescent woman was lowest among Nigerian women (16.28 I.9 years) and highest among Ghanaian women (I6.86 I I.8 years). However, the mean age of having first birth at any age was highest among Ghanaian women (19.58 3.8 years) and lowest among Liberian women (I7.75 \pm 3.3 years).

As expected, the mean number of births previously had by women who began childbearing as adolescent was higher than the estimate for all women who had their first birth at any age in all the countries. An indication that Women who started childbearing postponed birth till after adolescent years will have lower mean number of children previously born to them. The mean number of previous births for women who started childbearing as adolescent was highest in Nigeria $(5.16 \pm 2.8)$ and lowest in Ghana (4.19 2.3$)$ but the estimate for Gambia (4.67 \pm 2.5$)$ and Liberia $(4.69 \pm 6.7)$ was approximately the same. However, in this instance, Liberia women (4.II \pm 2.7$)$ had highest mean number of previous births compared to other countries while Ghanaian women $(3.00 \pm 2.4)$ had the least.

Table 2: Mean age at first birth and mean number of previous births among women who began childbearing as adolescent and at any age according to country of residence

\begin{tabular}{|c|c|c|c|c|c|c|c|c|}
\hline \multirow{3}{*}{$\begin{array}{l}\text { Age } \\
\text { Cohorts }\end{array}$} & \multicolumn{2}{|l|}{ Nigeria } & \multicolumn{2}{|l|}{ Ghana } & \multicolumn{2}{|l|}{ Gambia } & \multicolumn{2}{|l|}{ Liberia } \\
\hline & $<20$ years & All ages & $<20$ years & All ages & $<20$ years & All ages & $<20$ years & All ages \\
\hline & $\bar{x} \pm \sigma$ & $\bar{x} \pm \sigma$ & $\bar{x} \pm \sigma$ & $\bar{x} \pm \sigma$ & $\bar{x} \pm \sigma$ & $\bar{x} \pm \sigma$ & $\bar{x} \pm \sigma$ & $\bar{x} \pm \sigma$ \\
\hline $20-24$ & $16.29 \pm 1.8$ & $17.00 \pm 2.4$ & $16.85 \pm 1.7$ & $17.87 \pm 2.3$ & $16.46 \pm 1.9$ & $|7.4| \pm 2.6$ & $16.41 \pm 1.7$ & $16.97 \pm 2.2$ \\
\hline $25-29$ & $16.20 \pm 1.8$ & $17.84 \pm 3.2$ & $16.92 \pm 1.8$ & $19.19 \pm 3.3$ & $16.52 \pm 1.9$ & $18.32 \pm 3.2$ & $16.56 \pm 1.9$ & $|7.6| \pm 2.7$ \\
\hline $30-34$ & $16.24 \pm 1.8$ & $18.48 \pm 3.8$ & $16.71 \pm 1.8$ & $19.46 \pm 3.8$ & $|6.4| \pm 2.0$ & $18.48 \pm 3.6$ & $16.40 \pm 1.8$ & $17.69 \pm 3.0$ \\
\hline $35-39$ & $16.35 \pm 1.9$ & $18.98 \pm 4.1$ & $16.95 \pm 1.7$ & $20.03 \pm 4.0$ & $16.19 \pm 2.0$ & $18.42 \pm 3.9$ & $16.37 \pm 1.8$ & $17.98 \pm 3.4$ \\
\hline $40-44$ & $16.30 \pm 1.9$ & $19.16 \pm 4.4$ & $16.85 \pm 1.8$ & $19.64 \pm 4.0$ & $16.12 \pm 1.9$ & $|8.54 \pm 4|$. & $16.14 \pm 1.9$ & $17.88 \pm 3.6$ \\
\hline $45-49$ & $16.22 \pm 1.9$ & $18.92 \pm 4.4$ & $16.87 \pm 1.8$ & $19.84 \pm 4.1$ & $16.26 \pm 1.9$ & $18.70 \pm 4.2$ & $16.10 \pm 1.8$ & $17.87 \pm 3.9$ \\
\hline $20-49$ & $16.28 \pm 1.9$ & $18.60 \pm 4.0$ & $16.86 \pm 1.8$ & $19.58 \pm 3.8$ & $16.32 \pm 2.0$ & $18.39 \pm 3.7$ & $16.32 \pm 1.8$ & $17.75 \pm 3.3$ \\
\hline$F$-value & $13.392 *$ & $556.7^{*}$ & $5.234^{*}$ & $78.031 *$ & $19.582 *$ & $38.73 I^{*}$ & $35.437^{*}$ & $40.430 *$ \\
\hline $\bar{x} N O B$ & $5.16 \pm 2.8$ & $3.78 \pm 3.0$ & $4.19 \pm 2.3$ & $3.00 \pm 2.4$ & $4.67 \pm 2.5$ & $3.37 \pm 2.7$ & $4.69 \pm 6.7$ & $4.1 I \pm 2.7$ \\
\hline
\end{tabular}

$\bar{x}$ NOB: Mean number of births; *Significant at $0.1 \%$

In Figures 3(a-e), the data show the comparison of birth progression rate between women ages between 45-49 years who began their childbearing as adolescent and those who started theirs at the age of 20 years or more. When this was compared in each country, the data is evident that women who started childbearing as adolescent had higher birth progression rate through all the parities than their counterparts who postponed childbearing till after adolescent periods. This pattern was similar across all the countries included in this study. As expected, in all the countries, the birth progression rate reduces as the parity increases irrespective of the timing of the first birth. The birth progression rate among those who had their first birth as adolescent and those who had theirs at later years approached zero at parity 10 in Ghana and Gambia while in Nigeria and Liberia, their data show some tendencies of bearing more children after a woman had had her I0th child.
In Figures $3 e$ and $3 f$, among the women ages 45-49 years who began their childbearing as adolescent, the rate at which such women progressed in childbearing from parity I-10 was lowest in Ghana, followed by Gambia, Liberia and highest among Nigerian women. Although, the birth progression rates for parities I-I0 were almost the same among the Liberia, Gambia and Nigeria, the estimates for Nigeria and Liberia were closer particularly for parities 2-3 and 7-10. For women who had their first birth at ages 20 years and above, the birth progression rates were lowest among Ghanaians compared to that of other three countries. The pattern exhibited by Nigeria and Gambia women showed an indication of similarity in birth progression rates for parities between 2 nd and 5 th inclusive and from 8th to 10th parities while Liberia and Nigeria had almost equal birth progression rate for parities 5 to 10 . 
Figure 3: Births Progression Rate among women aged 45-49 years who had their first birth during adolescent period ( $\mathrm{I}-19$ years) and those who had theirs later ( 20 years and above)

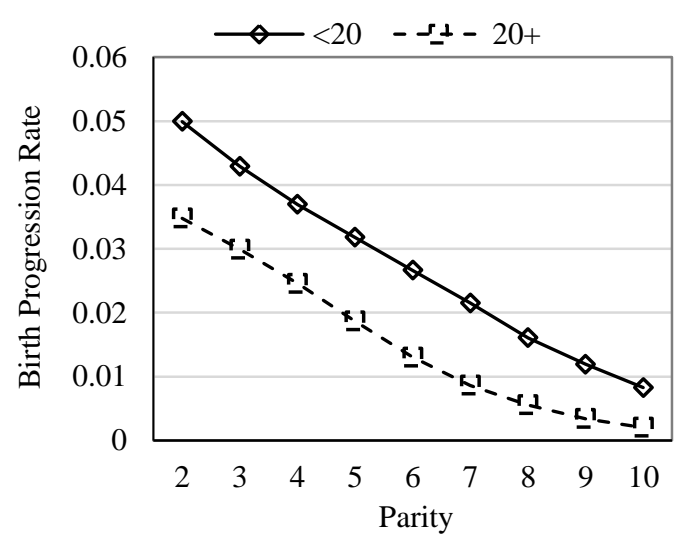

Figure 3a: Births Progression Rate [Nigeria]

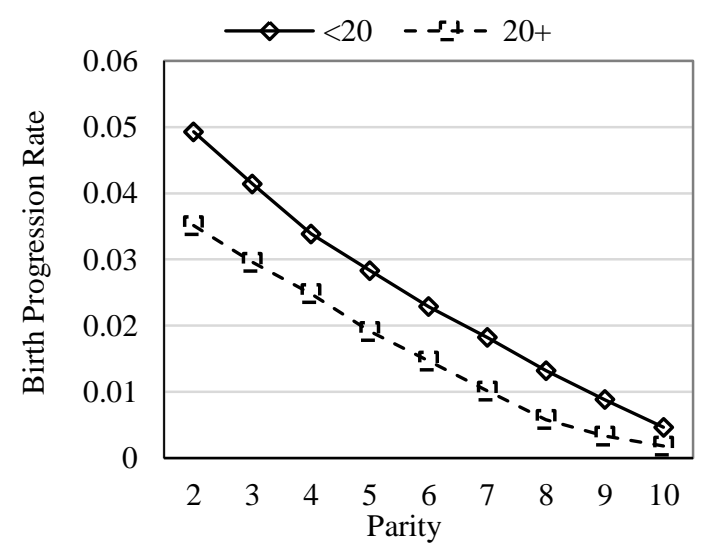

Figure 3c: Births Progression Rate [Gambia]

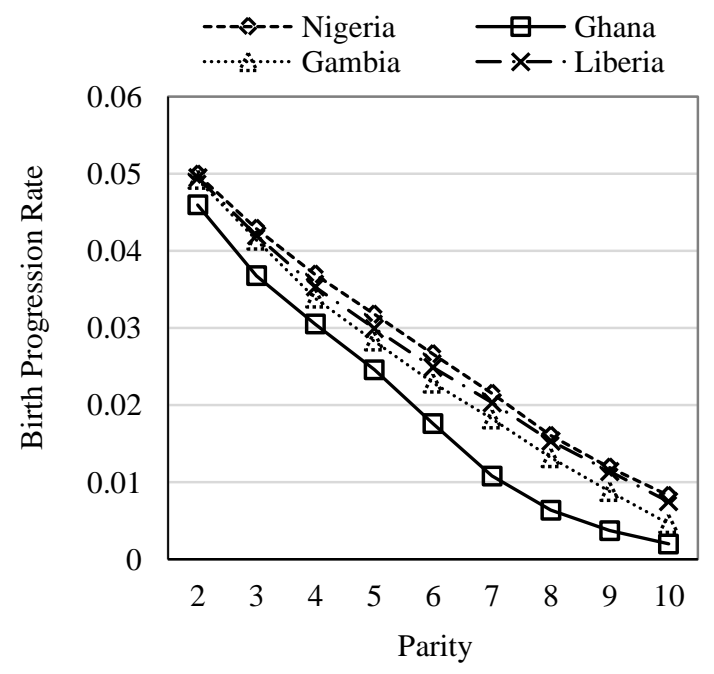

Figure 3e: Births Progression Rate [ 20 years]

The multivariate analysis on the dataset shows that the hazard of having first birth during adolescent was higher among women in the age cohort 20-24 years than the oldest age cohort (45-49 years). In Nigeria, having controlled for specific variables, the hazard ratio of AFB among age cohorts $20-24$ years was http://aps,journals.ac.za

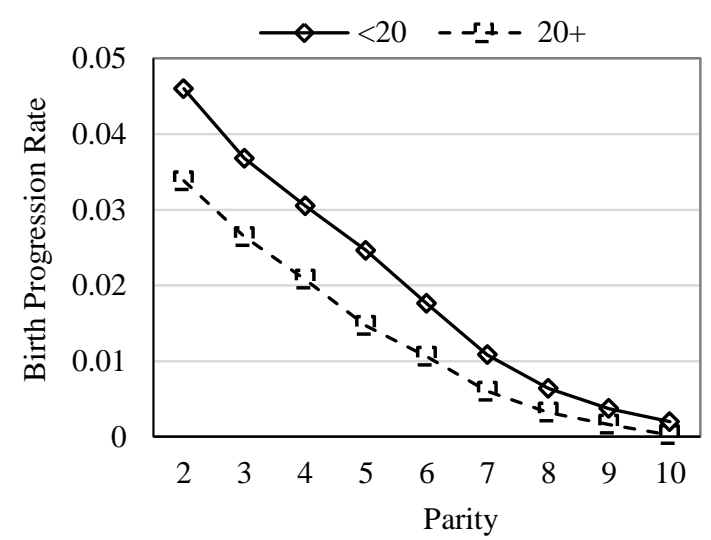

Figure 3b: Births Progression Rate [Ghana]

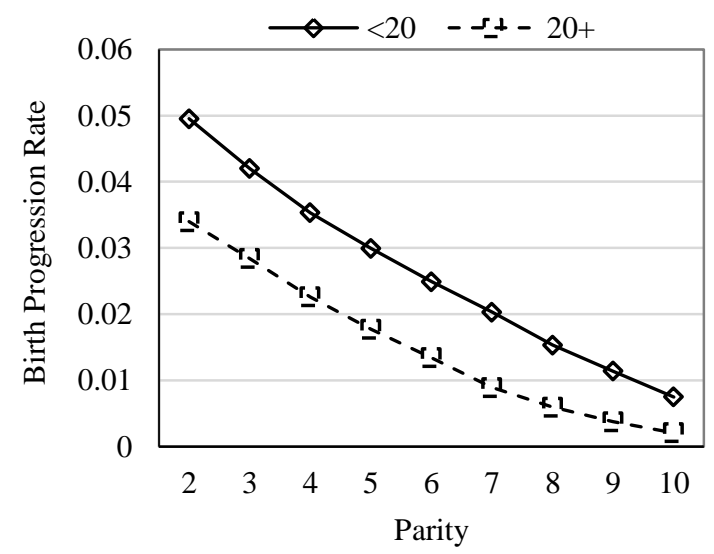

Figure 3d: Births Progression Rate [Liberia]

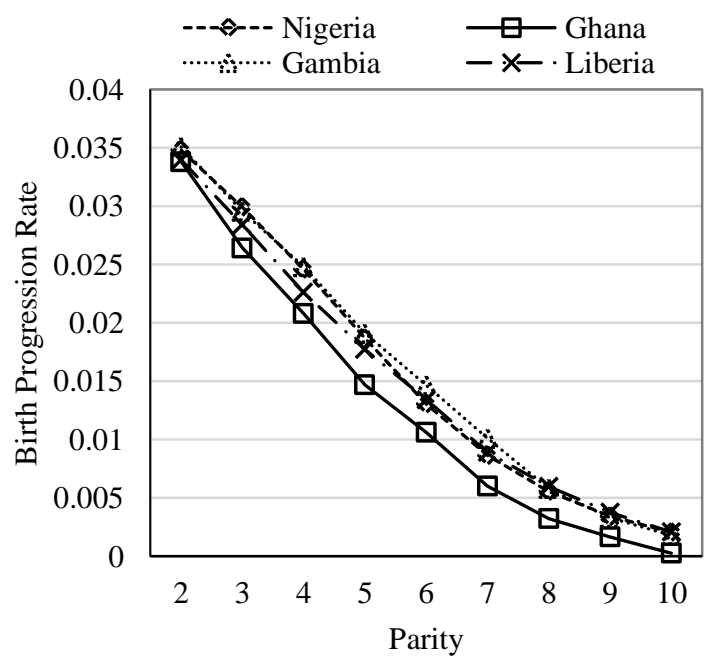

Figure 3f: Births Progression Rate [ 20 years]

I.49(C.I $=$ I.40-I.58, $\mathrm{p}<0.00 \mathrm{I})$ times higher than that of those in age group 45-49 years. This was the pattern exhibited in all the four countries, but the ratio was highest in Ghana. Also, in these countries, to some extent, the hazard ratio of adolescent first birth reduces as the birth cohort reduces but rises 
consistently among the younger women's birth cohort. For instance, in Ghana, the hazard ratio of AFB was I.05(0.9I-I.19), 0.84(0.74-0.96), 0.90(0.78I.02), $0.92(0.8 \mathrm{I}-\mathrm{I} .05)$ and $1.49(\mathrm{I} .30-\mathrm{I} .69)$ times likely among women in the birth cohort 40-44, 35$39,30-34,25-29,20-24$ years than that of women in birth cohort 45-49 years. In Nigeria and Gambia, the hazard of bearing first child during adolescent periods was higher among the Muslims than the Christians and this was statistically significant with Nigeria data. The converse pattern, although not statistically significant was exhibited among Ghanaians and Liberians.

With respect to women's education, as expected, the hazard ratio of AFB reduces as the level of education increases across the countries. However, variation existed in the pattern within each of the countries. In all the countries, the risk of AFB was strikingly higher among women who have no formal education and those with primary education than their counterparts with higher education. In Ghana for instance, the hazard of adolescent first birth was 6.47(4.16-10.04, $\quad \mathrm{p}<0.00 \mathrm{I}), \quad$ 7.07(4.55-10.97, $p<0.00 \mathrm{I})$ and 4.53(2.93-6.98, $\mathrm{p}<0.00 \mathrm{I})$ among women with no formal education, primary and secondary respectively than those with higher education. While place of residence was a significant factor influencing AFB in Nigeria and Ghana, this variable remains unimportant in Gambia and Liberia. The hazard ratio was I.16(I.13-I.2I, $\mathrm{p}<0.001)$ and I.I7(I.06-I.29, $\mathrm{p}<0.0 \mathrm{I})$ higher among rural women in Nigeria and Ghana respectively compared to women residence in urban areas. In three of the countries, Nigeria, Ghana and Gambia, household wealth was significantly related to AFB and higher risks were consistently found among women in lower household wealth categories than those from households that their wealth was considered as rich. As found in Gambia, AFB hazard ratio was I.25(I.12I.40, $\mathrm{p}<0.00 \mathrm{I})$ among poor women and I.I5(I.02I.29, $\mathrm{p}<0.0 \mathrm{I})$ among the middle class times higher when compared with that of rich women (Table 3).

The hazard curve of patterns of AFB in relation to birth cohorts of women are shown in Figures 4(a-h) for all the countries. The data show slight disparity in the patterns whether or not the models adjusted for other variables. However, higher hazard ratio was found among the most recent birth cohort than the oldest birth cohort in all the countries.

\section{Discussion}

In this study, the level of Adolescent First Birth (AFB) was high in all the countries but highest in Liberia where three-quarter of women aged 20-49 years had their first birth as adolescent and least in Ghana. In the past, countries in West-Africa have been found to be among the top list of high adolescent childbearing in Africa where Niger tops the list with approximately half of women aged 20-24 years reporting at least a birth before the age of 18 (UNFPA, 20I3). This estimate is lower than a threefourth found in Liberia in the current study by women aged $20-49$ years. Wider coverage in age of women in this study may account for the difference between the AFB estimates in Liberia and Niger. Other possible reason could be that the older women who were included in this study sample in Liberia were likely to be in their active childbearing years during the internal war that ravaged the nation few decades ago. Adolescent pregnancy is one of the after-effects of war, this could explain the high incidence of adolescent childbearing found among Liberia women.

The changing in socio-economic situation of a country can facilitate variation in the incidence of some health and cultural vices including early childbearing between age cohorts (Dolo, 2008). The prevailing level of modern contraceptive adoption, state of youth friendly programmes, educational policies and access to sexual and reproductive health information or services have implications on adolescent childbearing (MEASURE DHS, 2015). If these persist within a period but disappear at another time in the same society, there is likelihood for cohort of young women and men in each specific period to be influenced by health challenges or gains present during their own time in response to environmental behavior (Sedgh et al., 2015).

In all the four studied countries, women birth cohorts of 1990-1993 mostly experience AFB and the incidence increased steadily among the birth cohorts within the period. An indication that AFB occurred more in the years between 2005 and 20II than any other period in adolescent history of all the women who participated in the study. As a measure of trend in AFB which will interest the planners in their quest for knowledge on past teenage birth situations for future plans and agenda on how to rise up to the possible challenges of adolescent childbearing in West-Africa.

This study further revealed that adolescent childbearing was more experienced in contemporary times than years back. 
Table 3: Cox-proportional model of adolescent first birth by background variables according to selected countries in West Africa

\begin{tabular}{|c|c|c|c|c|c|c|c|c|}
\hline \multirow{2}{*}{$\begin{array}{l}\text { Background } \\
\text { Variables }\end{array}$} & \multicolumn{2}{|l|}{ Nigeria } & \multicolumn{2}{|l|}{ Ghana } & \multicolumn{2}{|l|}{ Gambia } & \multicolumn{2}{|l|}{ Liberia } \\
\hline & UHR(95.0\% C.I) & $\operatorname{AHR}(95.0 \% \mathrm{C.I})$ & UHR(95.0\% C.I) & $\operatorname{AHR}(95.0 \%$ C.I) & UHR(95.0\% C.I) & $\operatorname{AHR}(95.0 \% \mathrm{C.I})$ & UHR(95.0\% C.I) & $\mathrm{AHR}(95.0 \% \mathrm{C.I})$ \\
\hline \multicolumn{9}{|l|}{ Age } \\
\hline $20-24$ & |.47(|.39-|.56)* & I.49(I.40-।.58)* & $1.49(1.30-1.69)^{*}$ & I.53(I.33-।.75)* & $1.09(0.95-1.23)$ & $1.26(1.10-1.44)^{*}$ & I.16(I.04-I.28)*** & I.22(I.09-|.36)* \\
\hline $25-29$ & $1.03(0.96-1.09)$ & $1.10(1.03-1.16)^{* *}$ & $0.92(0.8|-| .05)$ & $1.03(0.90-1.17)$ & $0.77(0.68-0.88)^{*}$ & $0.88(0.77-1.00)$ & $0.89(0.79-0.98)^{* * * *}$ & $0.93(0.83-1.03)$ \\
\hline $30-34$ & $0.94(0.88-0.99)^{* * * *}$ & $1.04(0.97-1.10)$ & $0.90(0.78-1.02)$ & $0.99(0.87-1.13)$ & $0.8 \mathrm{I}(0.7 \mathrm{I}-0.93)^{* * *}$ & $0.90(0.78-1.02)$ & $0.91(0.81-1.01)$ & $0.93(0.83-1.04)$ \\
\hline $35-39$ & $0.87(0.82-0.93)^{*}$ & $0.93(0.87-0.99) * * *$ & $0.84(0.74-0.96)^{* * *}$ & $0.91(0.79-1.03)$ & $0.922(0.80-1.05)$ & $0.96(0.83-1.09)$ & $0.91(0.81-1.01)$ & $0.92(0.82-1.03)$ \\
\hline $40-44$ & $0.89(0.83-0.95)^{*}$ & $0.92(0.86-0.98) * * * *$ & $1.05(0.91-1.19)$ & $1.07(0.93-1.22)$ & $1.01(0.87-1.16)$ & $1.03(0.88-1.18)$ & $0.98(0.87-1.02)$ & $0.99(0.88-1.11)$ \\
\hline $45-49$ & 1.00 & 1.00 & 1.00 & 1.00 & 1.00 & 1.00 & 1.00 & 1.00 \\
\hline \multicolumn{9}{|l|}{ Religion } \\
\hline Christian & & 1.00 & & 1.00 & & 1.00 & & 1.00 \\
\hline Muslim & & $1.26(1.21-1.32)^{*}$ & & $0.94(0.85-1.04)$ & & $1.20(0.94-\mid .52)$ & & $0.95(0.86-1.03)$ \\
\hline Others & & $1.01(0.86-1.18)$ & & $1.01(0.87-1.16)$ & & ss & & $0.85(0.7|-| .01)$ \\
\hline \multicolumn{9}{|l|}{ Education } \\
\hline None & & $3.83(3.42-4.28)^{*}$ & & $6.47(4.16-10.04)^{*}$ & & $5.34(3.73-7.64)^{*}$ & & I.86(।.45-2.37)* \\
\hline Primary & & $3.43(3.08-3.83)^{*}$ & & 7.07(4.55-10.97)* & & $4.89(3.39-7.04)^{*}$ & & $1.90(1.48-2.42)^{*}$ \\
\hline Secondary & & $2.07(1.85-2.30)^{*}$ & & $4.53(2.93-6.98)^{*}$ & & $2.73(1.89-3.92)^{*}$ & & I.53(I.20-I.95)** \\
\hline Higher & & 1.00 & & 1.00 & & 1.00 & & 1.00 \\
\hline \multicolumn{9}{|c|}{ Place of residence } \\
\hline Urban & & 1.00 & & 1.00 & & 1.00 & & 1.00 \\
\hline Rural & & $1.16(1.13-1.21)^{*}$ & & I.I7(I.06-I.29)** & & $0.94(0.84-1.03)$ & & $1.04(0.96-1.12)$ \\
\hline \multicolumn{9}{|c|}{ Household Wealth } \\
\hline Poor & & $|.2|(|.| 4-\mid .27)^{*}$ & & I.20(I.05-I.35)** & & I.25(I.I2-I.40)* & & $1.05(0.96-\mid .15)$ \\
\hline Middle & & $1.18(1 . \mid 1-1.24)^{*}$ & & |.32(I.|7-|.48)* & & I.15(I.02-I.29) ${ }^{* * * *}$ & & $1.01(0.91-1.11)$ \\
\hline Rich & & 1.00 & & 1.00 & & 1.00 & & 1.00 \\
\hline$-2 \log L L$ & 294567.104 & 289592.23 & 50954.410 & 50577.351 & 63308.092 & 63224.819 & 82727.697 & 82486.773 \\
\hline
\end{tabular}

*Significant at 0.1\%; **Significant at I.0\%; ***Significant at 5.0\%; Ss: Small sample; UHR: Unadjusted Hazard Ratio; AHR: Adjusted hazard ratio 
Figure 4: Unadjusted and adjusted survival pattern of adolescent first birth (AFB) by age cohorts

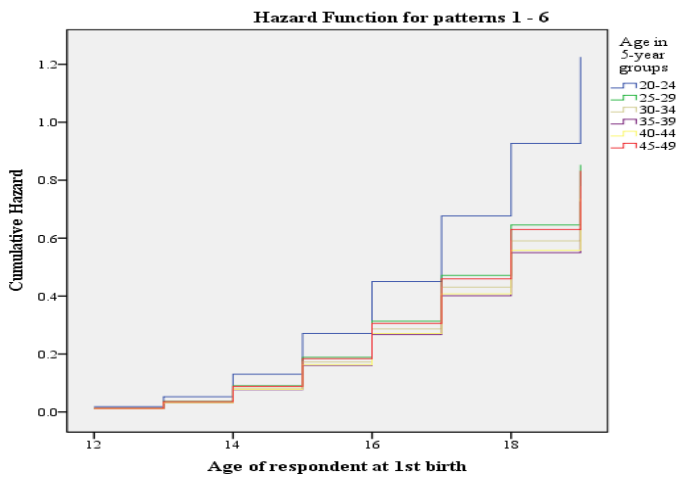

Figure 4a: Unadjusted survival pattern of AFB [Nigeria]

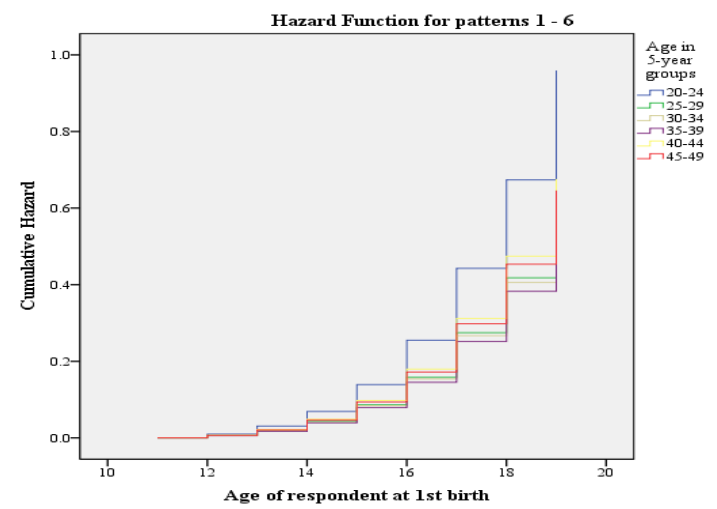

Figure 4c: Unadjusted survival pattern of AFB [Ghana]

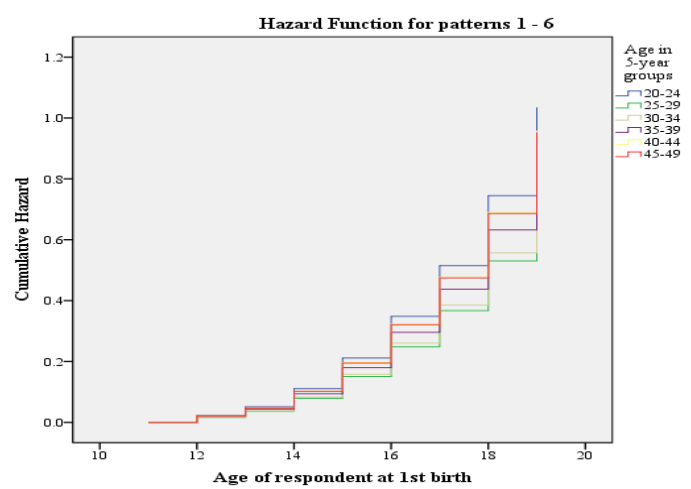

Figure 4e: Unadjusted survival pattern of AFB [Gambia]

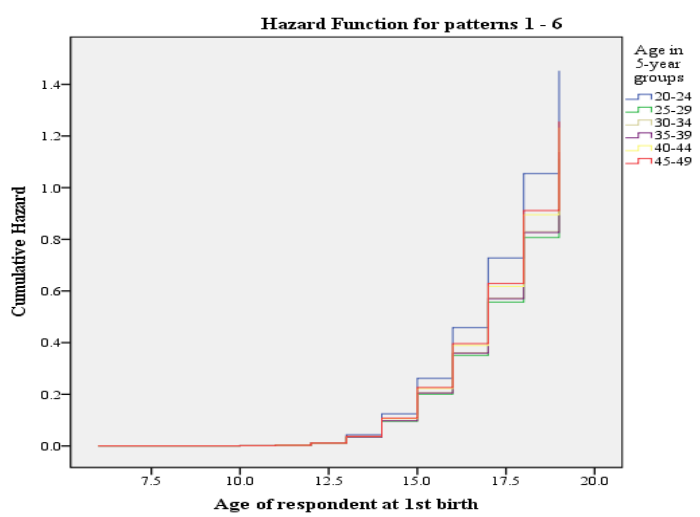

Figure 4g: Unadjusted survival pattern of AFB [Liberia]

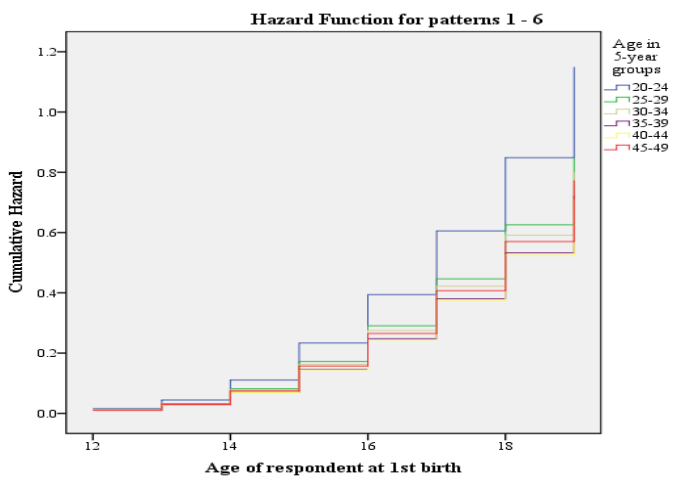

Figure 4b: Adjusted survival pattern of AFB [Nigeria]

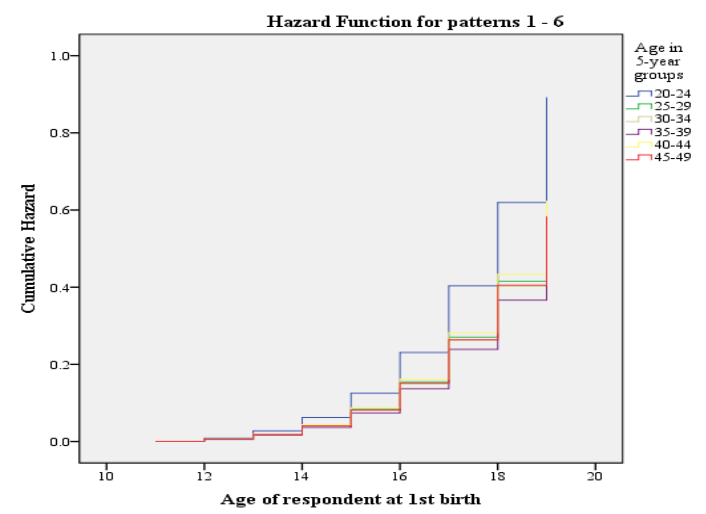

Figure 4d: Adjusted survival pattern of AFB [Ghana]

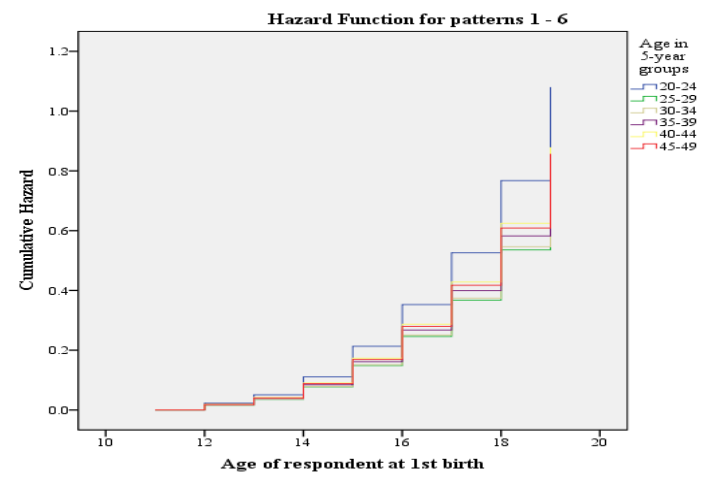

Figure 4f: Adjusted survival pattern of AFB [Gambia]

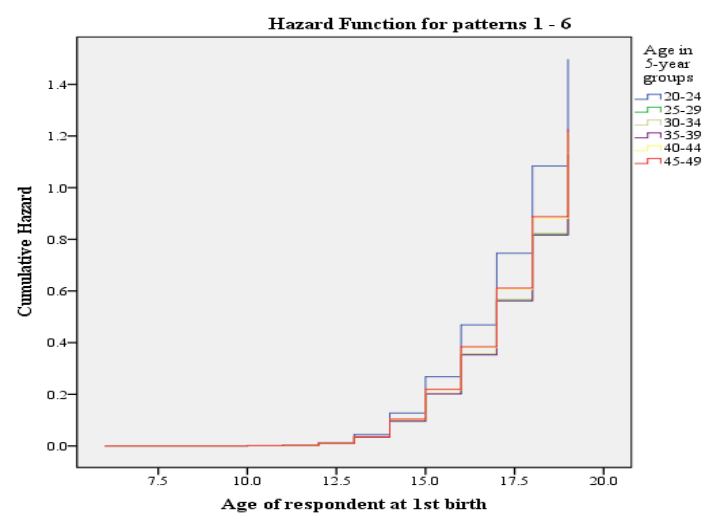

Figure 4h: Adjusted survival pattern of AFB [Liberia] 
For instance, among Nigerian women where the adolescent childbearing rate was found to be highest, from the onset of childbearing among cohort of women, an increment in year by one unit will increase the proportion of women who had their first birth during adolescent by 0.773 unit and least in Liberia where the rate was 0.497 . The multivariate output from this study supports this outcome. The finding is in agreement with the study by Kothari and colleagues (Kothari et al., 20I2).

In any country, the low income countries in particular, the proportion of women who had passed through adolescent periods without having first birth is an indicator of level of birth or marriage postponement which must have resulted from female school enrolment or improvement in the level of accessibility, acceptability and utilization of modern contraceptive among youths. These have both short and long term implication on fertility rate, women labor force participation rate and women empowerment (Xiaobo and Rong, 2016; Moschion, 2013). This study shows that the chance of surviving through adolescent years without having any child was consistently highest among Ghanaian women and lowest in Gambia but Nigeria and Liberia show similar experience. Consistently higher contraceptive prevalence rate and improvement in adolescent reproductive health services often reported in Ghana in the past decades than other countries included in this study might be the likely reason for Ghana's situation (Population Reference Bureau, 2016).

Information on the number of previous births echoes the accumulation of births of a woman's during her entire childbearing period but does not reflect the current level of fertility. However, as one of the fertility indicators, the mean number of previous births to all women is valuable for observing the variation in average family size across age groups and is assesses the level of primary childlessness. The outcome from this study shows that the mean number of previous birth by women who began childbearing during adolescent years was higher than those who commenced theirs after the period and this pattern was similar across the countries. This is expected since the year of exposure to the pregnancy risk will be less among those who commenced childbearing at years after adolescent period as a result of postponement and this has been widely reported in literature (Oyefara, 2012; HansPeter et al., 200I). Among women who experienced adolescent childbearing, Nigeria had the highest mean number of births, Ghana had the least while Gambia and Liberia estimates were almost the same. Wide disparity in age at first birth within Nigeria population is an important factor to consider why interpreting this result (National Population
Commission (Nigeria) and ICF International, 20I4). A region which contributes mostly to high adolescent childbearing in Nigeria is more in number than Ghana's population.

Women aged 45-49 years are assumed to be nearing the end of their childbearing period, their birth progression rate (BPR) was examined in this study. The BPR among this cohort of women is an indicator that provides a basis for deducing long-term trends in fertility (Adebowale et al., 20 I I). It gives an account on the fertility behavior of older women and serves as a pointer on how women who initiated childbearing in the three decades' prior the survey progressed from one parity to the other (Adebowale et al., 20II). In all the four countries, women who started childbearing as adolescent had higher BPR than those who began later and the BPR falls steadily with increasing parity. Across parities and irrespective of whether childbearing as an adolescent or not, Ghana consistently had the least BPR and Nigeria women experienced highest BPR.

The common predictors of AFB among the countries were; age and education and the pattern exhibited by the two variables were similar across the countries. While the risk of AFB was higher among women in age group 20-24 years than that of the women in the oldest age group (45-49). It is expected that the AFB should follow increasing trend due to availability and slight improvement in the use of modern pregnancy control measures in recent times than it used to be in the past few decades. The outcome of this study is in contrary to this assertion, recall bias on the part of older women because their first birth event took place in decades ago is the possible reason for the deviation from this expectation. There is also the likelihood of underreporting of AFB in the oldest age group. As for the education which revealed an indirect relationship with the risk of AFB, the pattern is well known and consistent with the literature (Adebowale et al., 2016; Aminul and Sayem, 2009; Kumar and Danabalan, 2006). In Nigeria for instance, the policy is that a pupil that is pregnant faces the risk of expulsion from school and as such in-school girls do all things possible to prevent pregnancy unlike their counterparts who are out-of-school. Schooling or educational prospects often lead to marriage postponement, thus reducing the risks of AFB among in-school women (Adebowale et al., 2016; Aminul and Sayem, 2009; Kumar and Danabalan, 2006).

\section{Limitation}

Despite some important outcomes emerging from this study, the data may not represent the true situation of adolescent childbearing in West-Africa countries due to culture specific nature of the issues 
associated with having first child as an adolescent. Therefore, the readers should interpret the findings with caution. As implicated by the cross-sectional nature of the study design, there is also possibility of recall bias on the part of older women regarding the exact AFB. In this context, the incidence of AFB among such women may either be over reported or underreported. In order to circumvent this situation, the data originators ensured that several questions relating to age, the day, the month and year of birth of the mother and first child were included in the original questionnaire used for this study.

\section{Conclusion}

Adolescent childbearing remains a problem in WestAfrica. There was variation in AFB across the four countries included in this study and fertility tends to be higher in the countries where its incidence or progression probability was higher. The adolescent childbearing among women in West-Africa countries follows an increasing trend. Education was identified as one of the important factors influencing AFB in the region.

\section{Program, Policy and Research}

Adolescent childbearing has implication for maternal and child health, and population growth rate. Government in West-Africa should strive to provide children with an enabling environment for the full realization of their rights and ensuring that adolescent sexual and reproductive health services are available and delivered. This will help the countries in the region to reap the demographic dividend and attain sustainable development goals. Undoubtedly, adolescent childbearing is a complex phenomenon and its dynamics has multidimensional causal factors. In resolving the discourses around adolescent childbearing, attention should be focused mainly on weakening the numerous streams of socioeconomic contributory factors. In some advanced nations where adolescent childbearing has declined, access to modern contraceptives and increased awareness of the risks associated with unprotected sex have been attributed to the success achieved.

Decision making capacities of the adolescent and programs that are entrenched in equipping youth with core traditional values that promote abstinence from sexual relations outside marriage among adolescent girls and boys in West-Africa countries should be strengthened. However, early and forced marriage common among some religious and cultural groups should be discouraged. Adolescent and community leaders training on sexual and reproductive health issues, embracing female education in totality might be the possible solutions to the issues surrounding high AFB in West-Africa.
This has been emphasized in the goal 3 (subtheme 3.7) of the sustainable development goals (United Nations, 20I5). UNFPA and other partners have been working with several countries to promote adolescent sexual and reproductive health in West Africa and many countries have policies and programmes to that effect, therefore such programmes and policies should be sustained in the region.

\section{Acknowledgements:}

The authors thank ICF International, USA for granting the approval of the data used for this study. They thank the Director of the Centre for Actuarial Research, Faculty of Commerce, University of CapeTown for sponsoring Dr. S.A. Adebowale (lead author of this paper) visit to the University. The manuscript of this paper was written and submitted to APS during this visit.

\section{Availability of Data and Materials:}

The datasets analyzed during the current study are available on measuredhs web platform, and could be accessed online at https://dhsprogram. com/data/available-datasets.cfm

\section{Competing interests}

The authors declare no competing interests.

\section{References}

Adebowale AS, Fagbamigbe AF, Adebayo AM. 2016. Regional Differences in Adolescent Childbearing in Nigeria. Journal of Population and Social Studies.

$$
\text { 24:101-116. }
$$

DOI

\section{I0.14456/jpss.2016.8}

Adebowale SA, Fagbamigbe FA, Bamgboye EA. $201 \mathrm{I}$. Contraceptive Use: Implication for Completed Fertility, Parity Progression and Maternal Nutritional Status in Nigeria, sub- Saharan Africa. African Journal of Reproductive Health. 15:60-68

Adebowale SA, Palamuleni ME, Yusuf BO, Okanlawon K. 2016. Women Educational Advancement in sub-Saharan Africa: Situation Analysis of Consequence of Double Harmful Socio-demographic Practices. British J of Education, Society \& Behavioral Science. 18: I-16

Alan Guttmacher Institute. 1996. Risks and Realities of Early Childbearing Worldwide. [Issues in Brief]. New York, NY: The Institute, 1996.

Aminul HM, Sayem AM. 2009. Socioeconomic determinants of age at first birth in rural areas of Bangladesh. Asia Pac J Public Health. 21 : 104-I I

Ashraf RE. 2005. An Examination of Factors Affecting Fertility Rate Differentials as Compared 
Among Women in Less and More Developed Countries. Kamla-Raj, J. Hum. Ecol. I8:181- 192

Balen FV, Bos HMW. 2009. The social and cultural consequences of being childless in poor-resource areas. Facts Views Vis Obgyn. I(2): I06-I 2 I.

Blum RW, Astone NM, Decker RM, Mouli CA. 2014. Conceptual framework for early

adolescence: a platform for research. International Journal of Adolescent Med Health. 26:32I-33I. doi: 10.15I5/ijamh-2013-0327

Clark S, Koski A, Smith-Greenaway E. 2017. Recent Trends in Premarital Fertility across Sub-Saharan Africa. Stud Fam Plann. 48(I):3-22. doi: 10. I I I I/sifp. I 2013.

Dolo E. 2016. Attending to Teen Pregnancy: Strengthening the Liberian Family System 2008 http://www.theliberianjournal.com/ index.phprid. Accessed December 2, 2016

Eshetu Gurmu, Dula Etana. 2014. Age at First Marriage and First Birth Interval in Ethiopia: Analysis of the Roles of Social and Demographic Factors. African Population Studies. Vol. 28(3):1332-1344.

Gibbs CM, Wendt A, Peters S, Hogue CJ. 20I2. The Impact of Early Age at First Childbirth on Maternal and Infant Health. Pediatrics Perinat Epidemiology. 26:259-284. doi:10.111 I/j. I3653016.20I2.01290.x

Garenne, M. 2008. Fertility changes in sub-Saharan Africa. DHS Comparative Reports No. 18. Calverton, Maryland, USA: Macro International.

Haaga J. 1989. Contraceptive Use and Controlled Fertility: Health Issues for Women and Children. Background papers. Parnellam (ed.) Committee on Population, National Research Council, Washington DC: National Academy Press. https://www.ncbi.nlm.nih. Accessed Feb. 3, 2017

Hans-Peter K, Axel S, Kaare C. 200I. The Age at First Birth and Completed Fertility Reconsidered: Findings from a Sample of Identical Twins. MPIDR Working Paper WP 200I- 006 March 200I

International Development Law Organization. 2010. Liberia Country Report: Strengthening the Legal Protection Framework for Girls in India, Bangladesh, Kenya and Liberia. http://www.idlo.int/doccalendar/liberiareport_fin al.pdf. Accessed February 6, 2017

International Planned Parenthood Federation. 2012. In their Own Words: Girls from Liberia on Sexuality, Pregnancy and Services. Foundation for Women's Health, Research and Development and International Planned Parenthood Federation. 2012
Isiugo-Abanihe UC. 1985. Child Fosterage in West Africa. Population and Development Review 1985; I I:53-73

Kothari MT, Shanxiao W, Sara KH, Noureddine A. 2012. Trends in Adolescent Reproductive and Sexual Behaviors. DHS Comparative Reports No. 29. Calverton, Maryland, USA: ICF International. 2012. Accessed February I, 2017

Kumar GA, Danabalan M. 2006. Determinants of Delayed First Birth. Indian J Community Med. 31:4-5

Magezi EB. 2017. Gendered character of barrenness in an African context: An African pastoral study. Vol 5I, No I. http://www.indieskriflig.org.

Marini MM. 198I. Effects of the Timing of Marriage and First Birth on Fertility. Journal of Marriage and Family. 43:27-46

Measure DHS. (2015). Median Age at First Birth. DHS Statistics Live. Available online at http://www.measuredhs.com. Accessed February 13, 2017

Mensch BS, Bruce J, Greene ME. 1998. The Uncharted Passage: Girls' Adolescence in the Developing World. New York: Population Council.

Moschion J. 2013. The Impact of Fertility on Mothers' Labour Supply in Australia: Evidence from Exogenous Variation in Family Size. Economic Record. 89:319-338

Mturi Akim J. 2015. Predisposing factors and consequences of childbearing among young unmarried women in North West, South Africa. African Population Studies. Vol. 29(2): 1954-1971.

National Population Commission (Nigeria) and ICF International. 20I4. Nigeria Demographic and Health Survey 2013. National Population Commission, Abuja, Nigeria.

Ngome E, Odimegwu C. 2014. The social context of adolescent women's use of modern contraceptives in Zimbabwe: a multilevel analysis. Reproductive Health. II:64. doi: 10.1 186/17424755-II-64

Odimegwu C, Mkwananzi S. 20I6. Factors associated with teen pregnancy in sub-Saharan Africa: a multi-country cross-sectional study. African Journal of Reproductive Health. 20(3):94- 107

Oyefara JL. 2012. Age at First Birth and Fertility Differentials among Women in Osun State, Nigeria. European Scientific Journal. 8:139-163

Pirk CM, Ana C, Alvarado B, Zunzunegui M. 20I4.Early maternal age at first birth is associated with chronic diseases and poor physical performance in older age: cross-sectional analysis from the International Mobility in Aging Study. BMC Public Health. 14:293-302 
Population Reference Bureau. 2016 World population data sheet with a special focus on human needs and sustainable resources. http://www.prb.org/pdf. Accessed February 13, 2017

Santelli JS, Song X, Garbers S, Sharma V, Viner RM. 2017. Global Trends in Adolescent Fertility, 1990-2012, in Relation to National Wealth, Income Inequalities, and Educational Expenditures. J Adolesc Health. 60(2): |6I-I68. doi: 10.1016/j.jadohealth.2016.08.026.

Sarah E Neal, Venkatraman C, Doris Chou. 2015. Adolescent first births in East Africa: disaggregating characteristics, trends and determinants. Reproductive Health. 12:13

Sedgh G, Finer LB, Bankole A, Eilers MA, Singh S. 2015. Adolescent Pregnancy, Birth, and Abortion Rates across Countries: Levels and Recent Trends. Journal of Adolescent Health. 56:223-230. http://ac.els-cdn.com

Singh, Susheela, and Jacqueline E. Darroch. 2000. "Adolescent Pregnancy and Childbearing: Levels and Trends in Developed Countries." Family Planning Perspectives. 32(I): I4-23.

Spence NJ. 2008. The Long-Term Consequences of Childbearing: Physical and Psychological WellBeing of Mothers in LaterLife. Res Aging. 30:72275I. doi:I0.1 I77/0164027508322575

Sneeringer, S. E. 2009. Fertility transition in subSaharan Africa: a comparative analysis of cohort trends in 30 countries. DHS Comparative Reports No. 23. Calverton, Maryland, USA: ICF Macro.

The statistical Annex. 2012. World Economic Situation and Prospects. http://www.un.org. Accessed February II, 2017
UNFPA. 2013. Africa has world's highest rate of adolescent pregnancies. http://www.africa progress panel. 2013 org /Africa -has-worldshighest-rate-of-adolescent-pregnancies-unfpasays/ Accessed February 13, 20I7United Nations. 20I I. United Nations Population Division, World Population Prospects: The 2010 Revision.

United Nations. 2013. Department of Economic and Social Affairs, Population Division. Adolescent Fertility since the International Conference on Population and Development (ICPD) in Cairo (United Nations publication).

United Nations. 2002. Department of Economic and Social Affairs, Population Division, United Nations (UN), World Population Prospects: The 2002 Revision, http://esa.un.org/unpp. Accessed February 3, 2017

United Nations. 2015. Draft outcome document of the United Nations summit for the adoption of the post-20I5 development agenda. Follow-up to the outcome of the Millennium Summit. http://www.un.org/ga/search/view_doc. 2015. Accessed January 13, 2017

World Population Prospect, 2016. Revision of World Population Prospects https://population.un.org/wpp/

Xiaobo H, Rong Z. 20I6. Fertility and Female Labour Force Participation: Causal Evidence from Urban China. 84:664-674

Zabin, LS and Karungari K. 1998. "Health Consequences of Adolescent Sexuality and Fertility Behavior in Sub-Saharan Africa." Studies in Family Planning. 29(2):2 I 0-232. 